\title{
Depression in Choroidal Melanoma Patients Treated with Proton Beam Radiotherapy
}

\author{
MARILITA M. MOSCHOS ${ }^{1,2^{*}}$, GIANNIS A. MOUSTAFA ${ }^{1 *}$, ANASTASIOS LAVARIS ${ }^{1}$, \\ CHRISTOS DAMASKOS ${ }^{3,4}$, KONSTANTINOS LAIOS $^{1}$, EKATERINI KARATHANOU ${ }^{5}$, DIMITRIOS S. LADAS ${ }^{1}$, \\ IOANNIS ASPROUDIS ${ }^{6}$, NIKOLAOS GARMPIS ${ }^{3,4}$ and CHRISTOS KALOGEROPOULOS ${ }^{6}$ \\ ${ }^{1}$ Department of Ophthalmology, University of Athens, Athens, Greece; \\ ${ }^{2}$ Biomedical Research Foundation, Academy of Athens, Athens, Greece; \\ ${ }^{3}$ Second Department of Propedeutic Surgery, Laiko General Hospital, Medical School, \\ National and Kapodistrian University of Athens, Athens, Greece; \\ ${ }^{4}$ N.S. Christeas Laboratory of Experimental Surgery and Surgical Research, Medical School, \\ National and Kapodistrian University of Athens, Athens, Greece; \\ ${ }^{5}$ Department of Ophthalmology, University of Larissa, Larissa, Greece; \\ ${ }^{6}$ Department of Ophthalmology, University of Ioannina, Ioannina, Greece
}

\begin{abstract}
Aim: To determine depression in patients with choroidal melanoma (CM) treated with proton beam radiotherapy. Patients and Methods: This was a cross-sectional study including 50 patients with CM $(50 \%$ males, mean age $=49.88 \pm 6.34$ years) and 46 age- and sex-matched healthy controls $(52 \%$ males, mean age $=48.60 \pm 8.05$ years $)$. Participants completed the Patient Health Questionnaire-9 (PHQ-9) and the Zung Self-Rating Depression Scale (SDS) questionnaires. Results: There was a considerable difference in visual acuity as logarithm of the minimum angle of resolution ( $\log M A R)$ between the patient and control groups $(1.16 \pm 0.97$ and $0.04 \pm 0.05 \log M A R$, respectively, $p<0.0001)$. Both $P H Q-9$ and SDS scores differed significantly between the two groups (10.18 \pm 4.68 and 8.07 $\pm 4.90, p=0.04$; and $47.94 \pm 12.56$ and $39.91 \pm 8.80, p=0.004$, respectively). Scores appeared to be positively correlated with $\log M A R$ visual acuity (Spearman rho=0.700, $p<0.0001$ for PHQ-9; and 0.767, $p<0.0001$ for $S D S$ ), and they were also correlated to each other (Spearman rho $=0.759, p<0.0001)$. Conclusion: Patients with CM having undergone proton beam therapy seem to be more depressed compared to a sample of healthy individuals, and the level of depression is correlated with their visual acuity.
\end{abstract}

\footnotetext{
*These Authors contributed equally to this study.

Correspondence to: Associate Professor Marilita M. Moschos, MD, Ph.D., 6 Ikarias Street, 14578, Ekali, Attica, Greece. Mobile: +30 6944887319, Fax: +30 2104122139, e-mail: moschosmarilita@yahoo.fr

Key Words: Choroidal melanoma, depression, PHQ-9, quality of life questionnaire.
}

Choroidal melanoma (CM) represents approximately $85 \%$ of uveal melanomas (1). Although a relatively rare tumor, it is the primary intraocular tumor in adults and appears more often in middle-aged Caucasians with a median age of 58 years (2). This tumor arises from melanocytes in the choroid, and usually presents with visual symptoms or is often diagnosed as an incidental finding upon ophthalmological examination. The most widely used treatment modalities for $\mathrm{CM}$ are enucleation, radioactive plaque brachytherapy, and proton beam radiotherapy. Treatment choice remains controversial in many respects. However, conservative treatments have gained much popularity and in selected cases they achieve similar outcomes to those of eye removal. Proton beam therapy offers the capacity to treat larger tumors compared with radioactive plaque therapy, and tumors located near the optic disc and fovea $(3,4)$. Compared to brachytherapy, proton beam therapy has the advantage of delivering a homogenous dose of radiation to the entire tumor. This is achieved through the physical properties of the accelerated proton particles, which are delivered precisely to the target tissue, resulting in a sharp fall of radiation dose beyond the delivery point, referred to as the Bragg peak phenomenon (5).

Until the 1990s, studies on CM mostly investigated the 'concrete' outcomes of treatment, such as survival or tumor recurrence, and little attention had been given to the psychological impact of the disease and the respective treatments. Five-year melanoma-related mortality reaches approximately $20-30 \%(1,6-8)$ and at least $61 \%$ of these patients will eventually die from melanoma (6). Moreover, visual acuity is significantly diminished through the course of the disease, even in patients receiving conservative 
treatments (8), and in cases of eye removal, concerns on esthetics may also be reported by patients. Such facts led researchers to realize that the emotional repercussions of the disease should be investigated.

The first attempt to explore psychological aspects in patients with CM was made in 1999 with the Quality of Life Substudy of the Collaborative Ocular Melanoma Study (COMS-QOLS), which observed that patients treated with iodine-125 brachytherapy were most likely to have symptoms of anxiety during follow-up compared with patients treated with enucleation (9-11). Since then, additional studies investigating the quality of life (QoL) of patients with ocular melanoma have been carried out. The majority explored the impact of the available therapies (12-21), while in recent years, a few studies also attempted to examine the impact of prognostic testing (22-24). Some of them have shown favorable results in terms of QoL, showing it to be similar to population normative values or not changing after treatment, even post enucleation $(11,14,15,25-27)$. Other studies claim that QoL significantly deteriorates both subsequent to the announcement of diagnosis and following treatment $(12,16-$ 19). Apparently, results on QoL and mental health status in patients with CM have been conflicting and inconclusive.

When examining for depression, data are even more sparse and diverse in regard to patients included, methods used and findings $(11,14,16,18,25,26)$. In a prospective study, HopeStone et al. used a sample of patients with malignant CM having received different treatments for their disease (including enucleation, ruthenium plaque brachytherapy, and proton beam brachytherapy) and compared it with normal individuals from published studies using the Hospital Anxiety \& Depression Scale (HADS) (14). Wiley et al. retrospectively examined depression in patients with CM treated with either enucleation, brachytherapy, or proton beam therapy, using the Center for Epidemiologic Studies Depression (CES-D) scale (25). In the study of Chabert et al., patients who were treated for CM with ruthenium brachytherapy or stereotactic external beam irradiation, either with the Leksell Gamma Knife or a 6MV LINAC, were included (18). Investigation for depression was carried out using the HADS (18). A French study examined only conservatively treated patients (iodine plaques or proton beam therapy) (26), while a study from Brazil assessed 20 patients treated surgically (enucleation), using the Beck Depression Inventory (16). In its third report, the COMS-QOLS compared patients who underwent enucleation or received iodine-125 brachytherapy with regard to the presence of depression and depression severity using the HADS (11). It seems that studies exploring depression in patients with malignant $\mathrm{CM}$ are limited and diverse. Moreover, only three of the previously discussed studies included patients who had received treatment with proton beam therapy, and these patients comprised only a small percentage of the whole sample $(14,25,26)$.
Table I. Demographics and medical characteristics of patients with choroidal melanoma and controls.

\begin{tabular}{lccc}
\hline & $\begin{array}{c}\text { Patients } \\
(\mathrm{n}=50)\end{array}$ & $\begin{array}{c}\text { Controls } \\
(\mathrm{n}=46)\end{array}$ & $p$-Value \\
\hline Age, years & $49.88 \pm 6.34$ & $48.60 \pm 8.05$ & 0.474 \\
Male sex & $25(50 \%)$ & $24(52 \%)$ & 0.831 \\
BCVA, affected eye, logMAR & $1.16 \pm 0.97$ & $0.04 \pm 0.05$ & $<0.0001$ \\
PHQ-9 score & $10.18 \pm 4.68$ & $8.07 \pm 4.90$ & 0.040 \\
SDS score & $47.94 \pm 12.56$ & $39.91 \pm 8.80$ & 0.004 \\
\hline
\end{tabular}

Data are presented as mean \pm standard deviation or number (\%). BCVA: Best-corrected visual acuity; PHQ-9: Patient Health Questionnaire-9; SDS: Zung Self-Rating Depression Scale.

The current study investigated depression in patients with malignant CM 5 years following treatment with proton beam radiotherapy. To our knowledge, this is the first study examining the psychological status of this subgroup of patients. We believe that our findings offer significant knowledge and hopefully will be a guide for clinicians when tackling psychological issues in such patients.

\section{Patients and Methods}

This was a cross-sectional study recruiting 50 patients with malignant CM followed-up at the First Department of Ophthalmology, University of Athens, Greece, and 46 age- and sex-matched controls without any ocular or systemic disease. Initially, patients were examined due to visual disturbances, or tumors were detected incidentally upon ophthalmologic examination. Fundoscopic examination, ultrasound and fluorescein angiography modalities were used for diagnosis. Patients had their disease diagnosed at the First Department of Ophthalmology and were subsequently sent to a specialized center in Switzerland to receive therapy with accelerated proton particles. All patients had completed at least 5 years post treatment follow-up and no metastatic disease was detected at surveillance workup, including hematological examinations, liver function tests, and abdominal ultrasound. Patients were asked to fill out questionnaires during their outpatient visit at our hospital and upon acceptance they were transferred to a quiet room to avoid distractions. The positive response rate was $100 \%$. The study was in accordance with the tenets of the Declaration of Helsinki and was approved by the Institutional Review Board of the G. Gennimatas General Hospital of Athens (No 1719). We certify that all applicable institutional regulations concerning the ethical use of human volunteers were followed during this research. Written informed consent was obtained by all participants.

All participants underwent a thorough ophthalmic examination, including best-corrected visual acuity (BCVA) measurement by means of Snellen charts, slit lamp biomicroscopy, and dilated fundoscopy. The questionnaires completed were the Patient Health Questionnaire-9 (PHQ-9) and the Zung Self-Rating Depression Scale (SDS) questionnaire. BCVA of the affected eye of the patients was compared with the corresponding eye of controls. For statistical purposes, the BCVA was converted into the logarithm of the minimum angle of resolution (logMAR) scale, with no perception of light being assigned a value of 3.0 . 
Table II. Spearman correlations between the examined variables in choroidal melanoma patients.

\begin{tabular}{|c|c|c|c|c|}
\hline & Age & Gender & BCVA, affected eye, logMAR & PHQ-9 score \\
\hline Gender & $-0.142(p=0.326)$ & & & \\
\hline BCVA, affected eye, logMAR & $0.042(p=0.773)$ & $0.096(p=0.506)$ & & \\
\hline PHQ-9 score & $0.040(p=0.784)$ & $-0.064(p=0.659)$ & $0.700(p<0.0001)$ & \\
\hline SDS score & $0.082(p=0.572)$ & $0.043(p=0.767)$ & $0.767(p<0.0001)$ & $0.759(p<0.0001)$ \\
\hline
\end{tabular}

BCVA: Best-corrected visual acuity; PHQ-9: Patient Health Questionnaire-9; SDS: Zung Self-Rating Depression Scale.

The PHQ-9 is a self-rating instrument used in clinical practice for measurement of the severity, monitoring and diagnosis of depression (28). It incorporates the criteria for major depression from the Diagnostic and Statistical Manual of Mental Disorders-IV (DSM-IV) assessing the patient's emotional status over the last 2 weeks (29). Responses are rated using a 4-category Likert scale: 0: "not at all", 1: "several days", 2: "more than half the days", and 3: "nearly every day", providing a continuous total score ranging from 0 to 27 . Scores of 4 or less indicate no depression, 5 to 9 mild depression, 10 to 14 moderate depression, 15 to 19 moderately severe depression, and 20 to 27 severe depression. The validity of the PHQ-9 have been well established both in the general population and in patients with visual impairment $(30,31)$.

The SDS is a short self-administered survey, structured on the basis of the most commonly found diagnostic criteria of depression and patient interviews, and used to quantify the depressed status of a patient (32). It consists of 20 items which are scored from 1 to 4 , if negative (e.g. "I feel down-hearted and blue"), or 4 to 1 , if positive (e.g. "I feel that I am useful and needed"), using the following scale: "a little of the time", "some of the time", "good part of the time", "most of the time". This type of reverse scoring is thought to limit response bias. The total raw score is derived by summing the individual scores for each item and ranges from 20 to 80. Individuals with a score of 49 or less are considered normal, 5059 mildly depressed, 60-69 moderately to markedly depressed, and 70 and above severely depressed. Research has shown SDS to be a sensitive and valid instrument for measuring and assessing depression both for research purposes and in clinical practice (33).

The normal distribution assumption was tested using the Kolmogorov-Smirnov and Shapiro-Wilk tests and all of the continuous variables (age, BCVA, PHQ-9 score, SDS score) failed to pass the normality test. Comparisons between patients and controls were performed using Mann-Whitney $U$-test. For categorical variables (sex), chi-square test was performed. The correlations of the PHQ-9 score and SDS score to age, BCVA and sex were analyzed using Spearman correlation test. The Statistical Package for the Social Sciences software version 20 (IBM Corp., Armonk, NY, USA) was used for statistical analysis. A $p$-value less than 0.05 was considered statistically significant.

\section{Results}

Fifty patients with malignant CM, 25 male and 25 female, with age ranging from 40 to 60 years, were included in our study. Additionally, 46 healthy volunteers, 24 male and 22 female, with age ranging from 40 to 60 , composed the control group. Mean age \pm standard deviation was $49.88 \pm 6.34$ and $48.60 \pm 8.05$ years for patients and controls, respectively. In patients, the mean $\log$ MAR BCVA of the affected eye was $1.16 \pm 0.97$ and was significantly higher (lower Snellen BCVA score) when compared with the corresponding eye of controls $(p<0.0001$, Mann-Whitney $U$-test $)$. A summary of participants' demographics and descriptive statistics is presented in Table I.

According to the PHQ-9 score, the percentage of patients with CM without depression was $14 \%$, with mild depression $28 \%$, moderate depression $36 \%$, and moderately severe depression $20 \%$, while $2 \%$ demonstrated severe depression. According to the SDS score, $52 \%$ of these patients had no depression, $24 \%$ were mildly depressed, $22 \%$ had moderate to marked depression, and $2 \%$ demonstrated severe depression.

PHQ-9 and SDS scores were found to be significantly different between the two groups, with patients being more depressed than controls ( $p=0.040$ and $p=0.004$, respectively).

Intercorrelations of the examined variables are shown in Table II. There was a strong positive correlation between the logMAR values and both PHQ-9 score and SDS score (Spearman rho $=0.700, p<0.0001$; and Spearman rho=0.767, $p<0.0001$, respectively). Considering this, the lower the BCVA in this group of patients, the higher the depression rating scale scores were. PHQ-9 was correlated positively with SDS score (Spearman rho $=0.759, p<0.0001$ ). Age and sex did not show any correlation with BCVA, PHQ-9 score and SDS score.

\section{Discussion}

Our study screened for depression a group of patients with non-metastatic malignant CM having completed 5 years post radiotherapy with accelerated proton particles and compared it with a group of healthy individuals. To our knowledge, this is the first targeted study examining patients having received this type of therapy and its results show them to be more depressed compared to controls. Descriptive analysis of our data shows that $58 \%$ of these patients scored 10 or above on the PHQ-9, a sensitive and specific cut-off for major depression (28), and $48 \%$ scored within the ranges of mild 
to severe depression with regard to the SDS. Remarkably, these rates are higher than those observed in other studies examining depression in patients with CM using different psychometric tests. Chabert et al. studied 98 patients 3 years following conservative treatment for $\mathrm{CM}$ and identified $14.4 \%$ with severe depression and $9.3 \%$ with borderline depression, whilst the rest of the sample was characterized as normal (18). However, the HADS used in this study, although good for anxiety detection, is considered weak in detecting depression, increasing the likelihood that the true prevalence of depression was underestimated (34). In addition, the binocular visual acuity was better than that of our patients (average 0.8 , ranging from 0.3 to 1 ), and visual acuity was strongly correlated with the level of depression in our study. Hope-Stone et al. also used the HADS questionnaire in patients with $\mathrm{CM}$ who had received several treatments $(17.5 \%$ received proton beam radiotherapy) to similarly observe lower depression rates compared to published normative values (14). Besides the poor predictive capacity of HADS, another explanation for low depression rates in their study could be the disproportionally high loss of patients with monosomy 3 , who were initially found to have a more depressed mood. A group from Brazil reported depression percentages similar to ours in the first few months following enucleation, yet significant mood improvement was achieved 1 year following surgery (16). Low prevalence of clinical depression was also observed in a study which included patients who had been treated for CM in the 5-year period prior to the study (25). Of course, the diversity in the samples, interventions, and outcomes evaluated make it difficult to clearly compare between these studies.

The depression scale scores in our study are also higher compared to those obtained for PHQ-9 and SDS questionnaires both in the general population and in patients with other types of cancer (35-39). This may be explained by the very low mean BCVA in our CM sample $(1.16 \pm 0.97$ $\log$ MAR) and the high prevalence of loss of light perception (10 of 50 patients). In our results, $\log$ MAR values demonstrated a strong and significant positive correlation with the scores of both types of depression rating scales, meaning that as visual acuity decreases (logMAR increases) patients become more depressed. This is also supported by other studies (40-43).

Proton beam radiation is a type of radiotherapy used to provide effective tumor control while preserving the eye and ensuring less discomfort and disability for the patient. Potential advantages are the homogenous tumor dose delivery and sharp dose fall-off outside the target region, which results in minimal scatter and confined damage of the adjacent area. Nevertheless, visual loss is fairly common in patients treated this way, due to a combination of inevitable injury of radiosensitive structures proximal to the tumor, tumor location, tumor growth, malignancy progression, and associated secondary effects. Indeed, approximately half of the patients end up with visual acuity less than 20/200 at 58 years post-treatment $(3,4,44-46)$. This should be a crucial and determining factor in terms of their mood and psychological well-being and possibly explains the high frequency of depression in our sample. Since visual acuity deteriorates with time and this is accompanied by increasing rates of depression, it would be reasonable also to test these patients early after proton beam radiation therapy to determine the prevalence and severity of depression early after treatment. These patients should also be assessed later when they have developed metastases, as advanced malignancy and the presence of metastases increase the risk for depression and psychological distress (47-52). In such cases, depression may be more common and more severe.

Another interesting finding of our study is that PHQ-9 score was positively correlated with SDS score and this intercorrelation was strong and significant. We observed similar results in our previous psychometric study on patients with retinitis pigmentosa, indicating that these two scales may have similar predictive capacity for depression (53). The PHQ-9 is considered a valuable and reliable tool for assessing depressive symptoms in people with visual impairment (31), while the SDS is a well-established screening tool for the severity of adult depression and for monitoring treatment effectiveness (54). It has been used in various mental health areas including primary care, drug trials, and associated clinical, institutional, and research settings (32). PHQ-9 and the Beck Depression Inventory have the advantage of being consistent with DSM-IV criteria for major depression, as they examine a 2-week period and also include an item specific to suicidal ideation (55). However, the SDS is easy to administer and score, although some individuals may find the positive and negative item wording confusing. It has been proposed as a screening tool but not as a diagnostic measure of depressive disorder (55). Our study also showed that both questionnaires were reliable when detecting depression symptomatology in CM patients.

Research of depression in specific diseases offers significant knowledge to clinical practitioners enabling them to better handle issues of psychological nature in their patients. Information on depression prevalence, severity, and the impact of several treatments allows them to effectively advise patients prior to initiation of treatment and enables them to provide proper preventive measures in order to secure maintenance of mental health. Considering that depression often goes undetected in patients with cancer, such investigations are also important to keep clinicians alert for psychological aberrations $(38,56)$. Psychosocial interventions, such as psychoeducational techniques, behavioral training, psychotherapy, and group interventions, have been proposed by Reimer et al. as possible preventive 
and therapeutic measures (17), as they seem to contribute significantly both to mental and physical health outcomes in patients with cancer (57). Psychosocial interventions may also reduce depressive symptoms in adults with vision impairment (58), and low vision rehabilitation should also be considered in selected cases $(59,60)$.

Considering the rarity of patients with malignant CM treated with proton radiotherapy, our study included a relatively large number of participants. However, in statistical terms, our sample may be inadequate for statistical accuracy. This is evident in our control group, in which PHQ-9 scores were higher compared to other published values $(35,36)$. Another limitation is the cross-sectional design, which does not allow for causal inference and also precludes assessment of depressive symptoms at different stages of the disease. Finally, the results of this single-center study should be generalized with caution.

\section{Conclusion}

Depression is common in people with malignant CM a couple of years following proton beam radiotherapy and more severe compared to healthy individuals with intact vision. Visual acuity has the strongest correlation with the level of depression. Clinical practitioners should be alert for depressive symptomatology when dealing with these patients and potential depression should be managed in close cooperation with mental health professionals. For a complete understanding of these patients' emotional status, we suggest investigating depression early after proton beam radiation treatment and possibly at the stage of metastatic melanoma.

\section{References}

1 Singh AD, Turell ME and Topham AK: Uveal melanoma: trends in incidence, treatment and survival. Ophthalmology 118: 1881$1885,2011$.

2 Chattopadhyay C, Kim DW, Gombos DS, Oba J, Qin Y, Williams MD, Esmaeli B, Grimm EA, Wargo JA, Woodman SE and Patel SP: Uveal melanoma: From diagnosis to treatment and the science in between. Cancer 122: 2299-2312, 2016.

3 Caujolle JP, Mammar H, Chamorey E, Pinon F, Herault J and Gastaud P: Proton beam radiotherapy for uveal melanomas at nice teaching hospital: 16 years' experience. Int J Radiat Oncol Biol Phys 78: 98-103, 2010.

4 Damato B, Kacperek A, Chopra M, Campbell IR and Errington RD: Proton beam radiotherapy of choroidal melanoma: the Liverpool-Clatterbridge experience. Int J Radiat Oncol Biol Phys 62: 1405-1411, 2005.

5 Damato B and Coupland SE: Translating uveal melanoma cytogenetics into clinical care. Arch Ophthalmol 127: 423-429, 2009.

6 Kujala E, Makitie T and Kivela T: Very long-term prognosis of patients with malignant uveal melanoma. Invest Ophthalmol Vis Sci 44: 4651-4659, 2003.
7 Diener-West M, Earle JD, Fine SL, Hawkins BS, Moy CS, Reynolds SM, Schachat AP and Straatsma BR: The COMS randomized trial of iodine 125 brachytherapy for choroidal melanoma, III: initial mortality findings. COMS Report No. 18. Arch Ophthalmol 119: 969-982, 2001.

8 Shields CL, Shields JA, Cater J, Gunduz K, Miyamoto C, Micaily B and Brady LW: Plaque radiotherapy for uveal melanoma: long-term visual outcome in 1106 consecutive patients. Arch Ophthalmol 118: 1219-1228, 2000.

9 Quality of life assessment in the collaborative ocular melanoma study: design and methods. COMS-QOLS Report No. 1. COMS Quality of Life Study Group. Ophthalmic Epidemiol 6: 5-17, 1999.

10 Melia M, Moy CS, Reynolds SM, Cella D, Murray TG, Hovland KR, Hayman JA and Mangione CM: Development and validation of disease-specific measures for choroidal melanoma: COMS-QOLS report No. 2. Arch Ophthalmol 121: 1010-1020, 2003.

11 Melia M, Moy CS, Reynolds SM, Hayman JA, Murray TG, Hovland KR, Earle JD, Kurinij N, Dong LM, Miskala PH, Fountain C, Cella D and Mangione CM: Quality of life after iodine 125 brachytherapy $v s$. enucleation for choroidal melanoma: 5-year results from the Collaborative Ocular Melanoma Study: COMS QOLS Report No. 3. Arch Ophthalmol 124: 226-238, 2006.

12 Mouriaux F, Servois V, Parienti JJ, Lesimple T, Thyss A, Dutriaux C, Neidhart-Berard EM, Penel N, Delcambre C, Peyro Saint Paul L, Pham AD, Heutte N, Piperno-Neumann S and Joly F: Sorafenib in metastatic uveal melanoma: efficacy, toxicity and health-related quality of life in a multicentre phase II study. $\mathrm{Br}$ J Cancer 115: 20-24, 2016.

13 Klingenstein A, Furweger C, Muhlhofer AK, Leicht SF, Schaller UC, Muacevic A, Wowra B, Hintschich C and Eibl KH: Quality of life in the follow-up of uveal melanoma patients after enucleation in comparison to CyberKnife treatment. Graefes Arch Clin Exp Ophthalmol 254: 1005-1012, 2016.

14 Hope-Stone L, Brown SL, Heimann H, Damato B and Salmon P: Two-year patient-reported outcomes following treatment of uveal melanoma. Eye 30: 1598-1605, 2016.

15 Klingenstein A, Furweger C, Nentwich MM, Schaller UC, Foerster PI, Wowra B, Muacevic A and Eibl KH: Quality of life in the follow-up of uveal melanoma patients after CyberKnife treatment. Melanoma Res 23: 481-488, 2013.

16 Amaro TA, Yazigi L and Erwenne C: Depression and quality of life during treatment of ocular bulb removal in individuals with uveal melanoma. Eur J Cancer Care 19: 476-481, 2010.

17 Reimer J, Voigtlaender-Fleiss A, Karow A, Bornfeld N, Esser J and Helga Franke G: The impact of diagnosis and plaque radiotherapy treatment of malignant choroidal melanoma on patients' quality of life. Psycho-Oncology 15: 1077-1085, 2006.

18 Chabert S, Velikay-Parel M and Zehetmayer M: Influence of uveal melanoma therapy on patients' quality of life: a psychological study. Acta Ophthalmol Scand 82: 25-31, 2004.

19 Reimer J, Esser J, Fleiss A, Hessel A, Anastassiou G, Krausz M, Bornfeld $\mathrm{N}$ and Franke GH: Quality of life in patients with malignant choroidal melanoma after radiotherapy. Graefes Arch Clin Exp Ophthalmol 241: 371-377, 2003.

20 Brandberg Y, Kock E, Oskar K, af Trampe E and Seregard S: Psychological reactions and quality of life in patients with posterior uveal melanoma treated with ruthenium plaque therapy or enucleation: a one-year follow-up study. Eye 14: 839-846, 2000. 
21 Cruickshanks KJ, Fryback DG, Nondahl DM, Robinson N, Keesey U, Dalton DS, Robertson DM, Chandra SR, Mieler WF, Zakov ZN, Custer PL, Del Priore LV and Albert DM: Treatment choice and quality of life in patients with choroidal melanoma. Arch Ophthalmol 117: 461-467, 1999.

22 Schuermeyer I, Maican A, Sharp R, Bena J, Triozzi PL and Singh AD: Depression, anxiety and regret before and after testing to estimate uveal melanoma prognosis. JAMA Ophthalmol 134: 51-56, 2016.

23 Erim Y, Scheel J, Breidenstein A, Metz CH, Lohmann D, Friederich HC and Tagay S: Psychosocial impact of prognostic genetic testing in the care of uveal melanoma patients: protocol of a controlled prospective clinical observational study. BMC Cancer 16: 408, 2016.

24 Beran TM, McCannel TA, Stanton AL, Straatsma BR and Burgess BL: Reactions to and desire for prognostic testing in choroidal melanoma patients. J Genet Couns 18: 265-274, 2009.

25 Wiley JF, Laird K, Beran T, McCannel TA and Stanton AL: Quality of life and cancer-related needs in patients with choroidal melanoma. Br J Ophthalmol 97: 1471-1474, 2013.

26 Suchocka-Capuano A, Bredart A, Dolbeault S, Rouic LL, Levy-Gabriel C, Desjardins L, Flahault C and Bungener C: Quality of life and psychological state in patients with choroidal melanoma: longitudinal study. Bull Cancer 98: 97107, 2011 (in French).

27 Coroides D: Quality of life in patients with choroidal melanoma. Arch Soc Esp Oftalmol 83: 301-306, 2008.

28 Kroenke K, Spitzer RL and Williams JB: The PHQ-9: validity of a brief depression severity measure. J Gen Intern Med 16: 606-613, 2001.

29 Association AP: Mood Disorders. In: Diagnostic and Statistical Manual of Mental Disorders (DSM-IV). Washington, DC: American Psychiatric Association, pp. 320-329, 1994.

30 Martin A, Rief W, Klaiberg A and Braehler E: Validity of the Brief Patient Health Questionnaire Mood Scale (PHQ-9) in the general population. Gen Hosp Psychiatry 28: 71-77, 2006.

31 Lamoureux EL, Tee HW, Pesudovs K, Pallant JF, Keeffe JE and Rees G: Can clinicians use the PHQ-9 to assess depression in people with vision loss? Optom Vis Sci 86: 139-145, 2009.

32 Zung WW: A self-rating depression scale. Arch Gen Psychiatry 12: 63-70, 1965.

33 Biggs JT, Wylie LT and Ziegler VE: Validity of the Zung Selfrating Depression Scale. Br J Psychiatry 132: 381-385, 1978.

34 Hopwood P, Howell A and Maguire P: Screening for psychiatric morbidity in patients with advanced breast cancer: validation of two self-report questionnaires. Br J Cancer 64: 353-356, 1991.

35 Hinz A, Mehnert A, Kocalevent RD, Brahler E, Forkmann T, Singer S and Schulte T: Assessment of depression severity with the PHQ-9 in cancer patients and in the general population. BMC Psychiatry 16: 22, 2016.

36 Hartung TJ, Brahler E, Faller H, Harter M, Hinz A, Johansen C, Keller M, Koch U, Schulz H, Weis J and Mehnert A: The risk of being depressed is significantly higher in cancer patients than in the general population: Prevalence and severity of depressive symptoms across major cancer types. Eur J Cancer 72: 46-53, 2017.

37 Dugan W, McDonald MV, Passik SD, Rosenfeld BD, Theobald $\mathrm{D}$ and Edgerton S: Use of the Zung Self-Rating Depression Scale in cancer patients: feasibility as a screening tool. Psychooncology 7: 483-493, 1998.
38 Passik SD, Dugan W, McDonald MV, Rosenfeld B, Theobald DE and Edgerton S: Oncologists' recognition of depression in their patients with cancer. J Clin Oncol 16: 1594-1600, 1998.

39 Yamazaki S, Fukuhara S and Green J: Usefulness of five-item and three-item Mental Health Inventories to screen for depressive symptoms in the general population of Japan. Health Qual Life Outcomes 3: 48, 2005.

40 Evans JR, Fletcher AE and Wormald RP: Depression and anxiety in visually impaired older people. Ophthalmology 114: 283-288, 2007.

41 Rovner BW, Zisselman PM and Shmuely-Dulitzki Y: Depression and disability in older people with impaired vision: a follow-up study. J Am Geriatr Soc 44: 181-184, 1996.

42 Rovner BW and Ganguli M: Depression and disability associated with impaired vision: the MoVies Project. J Am Geriatr Soc 46: 617-619, 1998.

43 Ip SP, Leung YF and Mak WP: Depression in institutionalised older people with impaired vision. Int J Geriatr Psychiatry 15: 1120-1124, 2000.

44 Gragoudas ES: Proton beam irradiation of uveal melanomas: the first 30 years. The Weisenfeld Lecture. Invest Ophthalmol Vis Sci 47: 4666-4673, 2006.

45 Damato B, Kacperek A, Errington D and Heimann H: Proton beam radiotherapy of uveal melanoma. Saudi J Ophthalmol 27: 151-157, 2013.

46 Dendale R, Lumbroso-Le Rouic L, Noel G, Feuvret L, Levy C, Delacroix S, Meyer A, Nauraye C, Mazal A, Mammar H, Garcia P, D'Hermies F, Frau E, Plancher C, Asselain B, Schlienger P, Mazeron JJ and Desjardins L: Proton beam radiotherapy for uveal melanoma: results of Curie Institut-Orsay proton therapy center (ICPO). Int J Radiat Oncol Biol Phys 65: 780-787, 2006.

47 Canoui-Poitrine F, Reinald N, Laurent M, Guery E, Caillet P, David JP, Tournigand C, Lagrange JL, Bastuji-Garin S, Lemogne $\mathrm{C}$ and Paillaud E: Geriatric assessment findings independently associated with clinical depression in 1092 older patients with cancer: the ELCAPA Cohort Study. Psychooncology 25: 104$111,2016$.

48 Hyphantis T, Papadimitriou I, Petrakis D, Fountzilas G, Repana D, Assimakopoulos K, Carvalho AF and Pavlidis N: Psychiatric manifestations, personality traits and health-related quality of life in cancer of unknown primary site. Psychooncology 22: 2009-2015, 2013.

49 Mystakidou K, Parpa E, Tsilika E, Panagiotou I, Zygogianni A, Giannikaki E and Gouliamos A: Geriatric depression in advanced cancer patients: the effect of cognitive and physical functioning. Geriatr Gerontol Int 13: 281-288, 2013.

50 Valdes-Stauber J, Vietz E and Kilian R: The impact of clinical conditions and social factors on the psychological distress of cancer patients: an explorative study at a consultation and liaison service in a rural general hospital. BMC Psychiatry 13: 226, 2013.

51 Lien K, Zeng L, Zhang L, Nguyen J, Di Giovanni J, Popovic M, Jamani R, Cramarossa G, Culleton S and Chow E: Predictive factors for well-being in advanced cancer patients referred for palliative radiotherapy. Clin Oncol (R Coll Radiol) 24: 443-451, 2012.

52 Low CA and Stanton AL: Activity disruption and depressive symptoms in women living with metastatic breast cancer. Health Psychol 34: 89-92, 2015. 
53 Moschos M, Chatzirallis A and Chatziralli I: Psychological aspects and depression in patients with retinitis pigmentosa. Eur J Ophthalmol 25: 459-462, 2015.

54 Shafer AB: Meta-analysis of the factor structures of four depression questionnaires: Beck, CES-D, Hamilton and Zung. J Clin Psychol 62: 123-146, 2006.

55 Lee EJ, Kim JB, Shin IH, Lim KH, Lee SH, Cho GA, Sung HM, Jung SW, Zmimmerman M and Lee Y: Current use of depression rating scales in mental health setting. Psychiatry Investig 7: 170176,2010

56 Akincigil A and Matthews EB: National rates and patterns of depression screening in primary care: Results from 2012 and 2013. Psychiatr Serv 68(7): 660-666, 2017.

57 Fawzy FI, Fawzy NW, Arndt LA and Pasnau RO: Critical review of psychosocial interventions in cancer care. Arch Gen Psychiatry 52: 100-113, 1995.

58 van der Aa HP, Margrain TH, van Rens GH, Heymans MW and van Nispen RM: Psychosocial interventions to improve mental health in adults with vision impairment: systematic review and meta-analysis. Ophthalmic Physiol Opt 36: 584-606, 2016.
59 Goldstein JE, Jackson ML, Fox SM, Deremeik JT and Massof RW: Clinically meaningful rehabilitation outcomes of low vision patients served by outpatient clinical centers. JAMA Ophthalmol 133: 762-769, 2015.

60 Binns AM, Bunce C, Dickinson C, Harper R, Tudor-Edwards R, Woodhouse M, Linck P, Suttie A, Jackson J, Lindsay J, Wolffsohn J, Hughes L and Margrain TH: How effective is low vision service provision? A systematic review. Surv Ophthalmol 57: 34-65, 2012.
Received January 27, 2018

Revised March 11, 2018

Accepted March 15, 2018 